\title{
ESTÁGIOS DA GESTÃO PEDAGÓGICA PARA O USO DAS TECNOLOGIAS DIGITAIS
}

\author{
PEDAGOGICAL MANAGEMENT'S STAGES TOWARDS THE USE OF \\ DIGITAL TECHNOLOGIES
}

\author{
ETAPAS DE LA GESTIÓN PEDAGÓGICA PARA EL USO DE LAS \\ TECNOLOGÍAS DIGITALES
}

\begin{abstract}
Paula Patrícia Barbosa Ventura ${ }^{1}$; José Aires de Castro Filho²
\end{abstract}
\begin{abstract}
RESUMO
Este artigo tem como objetivo propor estágios da gestão pedagógica para o uso das tecnologias digitais quando as metodologias ativas são utilizadas. Tal proposta tomou por base os estágios de gerenciamento tecnológico de Sandholtz, Ringstaff e Dwyer (1997). De natureza qualitativa e assinalada como um estudo de caso, a pesquisa foi realizada numa instituição federal, nos semestres 2016.2 e 2017.1. Os participantes foram quatro professores pertencentes ao quadro efetivo. Como instrumentos, recorreu-se a um questionário de sondagem, à observação e à entrevista. Para a análise de dados, iniciou-se com as questões de menor amplitude, bem como se definiram códigos iniciais ou subsequentes. Fases como ordenação, classificação e análise propriamente dita do material também subsidiaram a análise. Posteriormente, foram triangulados os dados, sendo estes ancorados pelo paradigma interpretativo. Com base na literatura e na pesquisa empírica, foram propostos cinco estágios da gestão pedagógica - Iniciação, Inserção, Integração, Efetivação e Disrupção - demonstrando que os professores investigados oscilaram, no período da pesquisa, entre estágios elementares e intermediários quando da utilização das tecnologias de forma pedagógica. Neste sentido, ratifica-se a importância de desenvolver novos referenciais teóricos com base numa situação vivida, sendo maior a probabilidade de adoção por parte dos professores, aproximando teoria e prática. Acredita-se que se o docente desenvolve práticas fundamentadas nesses estágios, maiores serão as possibilidades de tornar o aluno corresponsável por sua aprendizagem.
\end{abstract}

PALAVRAS-CHAVE: Prática docente. Tecnologia. Gestão pedagógica.

\footnotetext{
${ }^{1}$ Doutora em Educação - Universidade Federal do Ceará (UFC). Fortaleza, CE - Brasil. Professora do Instituto Federal de Educação, Ciência e Tecnologia do Ceará (IFCE). Fortaleza, CE - Brasil. Email: paula.ventura@ifce.edu.br

${ }^{2}$ Doutor em Mathematics Education - University of Texas At Austin (U.T. AUSTIN). Estados Unidos. Professor da Universidade Federal do Ceará (UFC). Fortaleza, CE - Brasil. Email: aires@virtual.ufc.br

Submetido em: 11/06/2019 - Aceito em: 30/11/2019
}

(C) ETD- Educação Temática Digital Campinas, SP $\quad$ v.22 $\quad$ n.4 $\quad$ p. 1010-1030 out./dez. 2020 


\section{ABSTRACT}

This article's aim is to propose stages of pedagogical management towards the use of digital technologies when active methodologies are used. This proposal was based on technological management stages by Sandholtz, Ringstaff and Dwyer (1997). Conceived with a qualitative nature and pointed as a case study, the research was carried in a federal institution, during 2016.2 and 2017.1 semesters. The participants were four teachers from the permanent staff. As instruments, a survey questionnaire, observation and interviews were used. Regarding data analysis, it started with questions on a smaller scale as the initial or subsequent codes were defined. Phases like sorting, classification and analysis itself of the material also supported the analysis. Thus, the data were triangulated, being anchored by the interpretative paradigm. Based on literature and empirical research, five stages of pedagogical management were proposed - Initiation, Insertion, Integration, Effectivity and Disruption -, demonstrating that the investigated teachers fluctuated, during the research period, between elementary and intermediate stages when using the technologies in a pedagogical way. In this sense, the importance of developing new theoretical frameworks based on real situations is affirmed, with a greater probability of them being carried out by teachers, bringing theory and practice closer together. It is believed that if teachers develop practices based on these stages, there are greater possibilities of making students co-responsible for their own learning.

KEYWORDS: Teaching practice. Technology. Pedagogical management.

\section{RESUMEN}

Este artículo tiene como objetivo proponer etapas de la gestión pedagógica para el uso de tecnologías digitales cuando se utilizan metodologías activas. Esta propuesta se basó en las etapas de gestión tecnológica de Sandholtz, Ringstaff y Dwyer (1997). De naturaleza cualitativa y señalada como caso práctico, la investigación fue realizada en una institución federal, en los semestres 2016.2 y 2017.1. Los participantes fueron cuatro profesores pertenecientes a la plantilla. Como instrumentos, se recurrió a cuestionario de sondeo, la observación y la entrevista. Para análisis de datos, se inició con cuestiones de menor amplitud, así como se definieron códigos iniciales o subsiguientes. Fases como ordenación, clasificación y análisis propiamente dicho del material también subsidiaron el análisis. Posteriormente, fueron triangulados los datos, siendo éstos respaldados por el paradigma interpretativo. Basándose en la literatura e investigación empírica, se propusieron cinco etapas de gestión pedagógica - Iniciación, Inserción, Integración, Efectuación y Disrupción - demostrando que los profesores investigados oscilaron, en el período de la investigación, entre etapas elementales e intermedias utilizando las tecnologías de forma pedagógica. En este sentido, se ratifica la importancia de desarrollar nuevos referenciales teóricos basados en situación experimentada, aumentando la posibilidad de adopción por parte de los profesores, acercando teoría y práctica. Se cree que si el docente desarrolla prácticas fundamentadas en estas etapas, mayores serán las posibilidades de convertir al alumno en corresponsable por su aprendizaje.

PALAVRAS-CLAVE: Práctica docente. Tecnología. Gestión pedagógica.

(C) ETD-Educação Temática Digital Campinas, SP $\quad$ v.22 $\quad$ n.4 $\quad$ p. 1010-1030 out./dez. 2020




\section{INTRODUÇÃO}

Silva et al (2014) pontuam dificuldades que os professores encontram em lidar com as tecnologias digitais. Segundo os autores a maioria dos professores expressa um bom desempenho das tecnologias digitais em seu uso pessoal, mas ainda se encontram num processo de desenvolvimento quanto às suas competências de desempenho na gestão pedagógica, o que os situa em níveis iniciais de apropriação tecnológica. Revelaram, também, que os docentes necessitam desenvolver os seus conhecimentos e competências na área, para, em seguida, adequá-los pedagogicamente (SILVA et al., 2014).

Deste modo, a utilização pedagógica das tecnologias digitais nas metodologias de ensino, requer um planejamento que perpasse o uso pelo uso, tendo a tecnologia influência considerável nas estratégias de aprendizagem e na ativação dos processos mentais. A preocupação do professor deve "[...] ser orientada mais para a forma como o aluno interage com a informação, como desenvolve o modelo mental da informação e como a utiliza de forma significativa em novas tarefas, ou situações problema, do que para os modos de transmissão e as tecnologias de suporte" (DIAS, 1995, p.24).

Se os professores têm dificuldades que perpassam o uso pelo uso, o objetivo deste artigo é propor estágios da gestão pedagógica para o uso das tecnologias digitais quando as metodologias ativas são utilizadas. Tais metodologias são definidas por exigirem do discente o desenvolvimento de sua autonomia, a tomada de decisões e seu protagonismo em todo o percurso educativo. O vocábulo "ativo" diz respeito a construção, elaboração, sistematização e teorização do conhecimento, o que extingue a mera reprodução de conteúdos, pois, ao atuar em sua formação intelectual, o aluno estreita relações com o professor, fornecendo-lhe feedback de como quer aprender. Requer não somente um direcionamento do professor, ao ensinar, mas do estudante, também, para gerir a própria aprendizagem.

Tais estágios podem auxiliar o docente a (re)pensar suas metodologias de ensino, viabilizando a aprendizagem ativa. Para tanto, tomou-se como respaldo teórico os estágios de gerenciamento tecnológico de Sandholtz, Ringstaff e Dwyer (1997). Utilizar as tecnologias digitais nas metodologias, especialmente às ativas, não significa estar num cenário de inovação tecnológica ou pedagógica ou em ambas, tampouco desenvolver metodologias que privilegiem a autoria, a colaboração e participação ativa. Pelo contrário, a sua utilização requer mudança conceitual e das práticas desenvolvidas, constituindo, em grande parte, um dos motivos para a resistência à elaboração de novos cenários (DIAS, 2013).

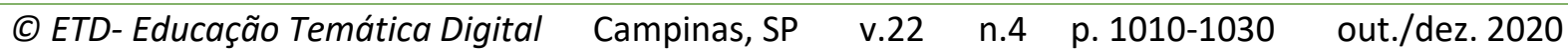


Justifica-se a necessidade dessa proposta para os docentes que atuam na Educação Superior, por se haver encontrado na literatura somente estágios de gerenciamento tecnológico, propostas de referenciais de competências em Tecnologias de Informação e Comunicação (TIC) para professores (SANDHOLTZ; RINGSTAFF; DWYER, 1997; ISTE, 2008; COSTA, 2008; UNESCO, 2009) e propostas de avaliação de estágios de integração das tecnologias no contexto escolar (VOSGERAU; PASINATO, 2013).

Pesquisas atuais também têm privilegiado o uso tecnológico quando da incorporação das tecnologias, na escolaridade mediada tecnologicamente, assim como no desenvolvimento da fluência tecnológica dos sujeitos no processo de ensino e aprendizagem (ABEGG; BASTOS, 2016). Ainda que os autores privilegiem a motivação, colaboração, criatividade e interação dialógico-problematizadora entre professor e aluno, características das metodologias ativas, a ideia deve ser a da perspectiva pedagógica se sobrepor a perspectiva tecnológica, caracterizando a relevância do aspecto pedagógico nas ações humanas quando mediadas pelas tecnologias.

Similar a esta proposta, Modelski, Giraffa e Casartelli (2019) investigaram o perfil dos docentes que empreenderam boas práticas com o uso pedagógico das tecnologias, especificando a competência fluência digital como mentora desta publicação. Os resultados demonstraram que os professores possuem níveis de familiaridade diferenciados quanto ao uso de tecnologias, mas evidenciaram restrições no que diz respeito a aspectos didáticopedagógicos. Ainda que reconheçam que o uso instrumental seja necessário, o viés pedagógico deve estar expresso no fazer docente. Outros autores, apesar de defenderem a apropriação pedagógica das tecnologias e que elas já façam parte da proposta curricular e estejam integradas pedagogicamente na prática docente (ALMEIDA; VALENTE, 2011; SILVA et al., 2014; ROSA; AZENHA, 2015), não foram encontrados na literatura estágios da gestão pedagógica.

Sobre os estágios de gerenciamento tecnológico, Sandholtz, Ringstaff e Dwyer (1997) elaboraram cinco estágios de uso da tecnologia. São eles: exposição ou entrada; adoção, adaptação, apropriação e inovação ou invenção, respectivamente. No estágio inicial, exposição ou entrada, os autores destacam que pouca ou nenhuma experiência os professores possuíam com o uso do computador, embora manifestassem interesse em seu emprego e estivessem preocupados com a própria adequação. Ao final deste estágio, os professores já dominavam o básico da tecnologia.

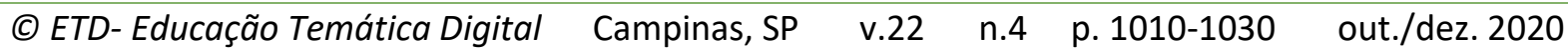


No dois, a adoção, a preocupação dos docentes não mais estava concentrada em si mesmo e em sua capacidade de manter o controle da sala de aula e dos alunos, mas em integrar a tecnologia em seus planos de aula, incorporando em suas aulas atividades baseadas no computador, objetivando ensinar os alunos a utilizarem a tecnologia. Ainda assim, os professores mantêm a aula tradicional e trabalham individualmente, sendo o objetivo da tecnologia apoiar as práticas. No três, a adaptação, a tecnologia tornaram-se totalmente integrada na prática tradicional em sala de aula, com o uso de processadores de palavras, banco de dados, programas gráficos e "pacotes" instrucionais assistidos por computador (CAI). Ainda que houvesse essa integração, a predominância era das aulas expositivas (SANDHOLTZ; RINGSTAFF; DWYER, 1997).

O quatro, apropriação, é caracterizado por mudança de atitude pessoal em relação ao uso da tecnologia. Essa mudança decorre porque os professores começam a entender "como" utilizar a tecnologia sem maiores dificuldades, introduzindo novas práticas pedagógicas. No estágio cinco, inovação ou invenção, os professores experimentam novos padrões instrucionais e formas de se relacionarem com os alunos e com outros professores, tornando aqueles mais ativos, curiosos e confiantes nas salas de aulas. A ideia dos autores foi criar diferentes formas de ensinar e aprender com o auxílio da tecnologia, considerando o contexto de ensino, as concepções dos professores sobre o ensino e a aprendizagem (e as dificuldades em alterar estas crenças), os papéis do docente e discente ao utilizarem as tecnologias e a relevância de aperfeiçoamento profissional na instituição.

Se as tecnologias suscitarem a participação ativa, tanto do professor quanto do aluno, no que diz respeito à mobilização de ideias, pensamentos e (re)significações de um saber inicial sobrepondo ao saber técnico, geralmente inerte e aperfeiçoado com o uso contínuo, seu uso fará sentido porque o professor saberá onde se quer chegar (fins) visando à aprendizagem do discente.

Estruturalmente o artigo está dividido em quatro partes. Nas considerações introdutórias, discute-se os estágios de gerenciamento tecnológico como fundamento para a elaboração dos estágios da gestão pedagógica. Na segunda parte, descreve-se o método. $\mathrm{Na}$ terceira parte, apresentam-se os resultados e a discussão dos dados. Por último, algumas considerações são feitas.

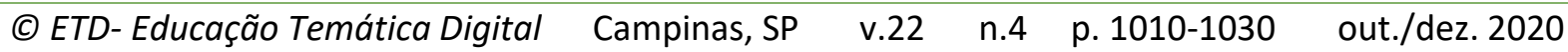




\section{MÉTODO}

De natureza qualitativa e caracterizada como um estudo de caso (YIN, 2010), a pesquisa, oriunda de uma tese de doutorado e defendida em março de 2019 , foi desenvolvida no Instituto Federal de Educação, Ciência e Tecnologia do Ceará, campus Camocim - CE, lócus onde se atuou como docente ao ingressar no serviço público federal. Os participantes foram escolhidos com base num questionário aplicado a todos no encontro pedagógico de docentes. O objetivo deste instrumento foi o de mapear o perfil dos professores que se utilizavam das tecnologias digitais, quais eram estas tecnologias e a frequência com que eram utilizadas nas ações dos docentes. Somado a essas três questões, o questionário continha as credenciais do professor, o tempo de docência, o interesse em participar da pesquisa e contatos pessoais a serem fornecidos, caso houvesse disponibilidade na participação.

Dos 23 professores do campus Camocim, quatro foram escolhidos para participar da pesquisa segundo três critérios: tempo na carreira docente, utilização das tecnologias digitais na prática pedagógica e disponibilidade em participar da pesquisa. Destaca-se que o tempo de docência foi um dos critérios por se compreender que, na prática, os saberes docentes são constituídos, ressignificados e validados (TARDIF, 2002). Os quatro professores selecionados foram denominados de P1, P2, P3 e P4 e possuíam formação acadêmica nas áreas de Geografia, Pedagogia, Física e Engenharia Ambiental, respectivamente, sendo três doutores (na época da coleta de dados um deles era doutorando) e um mestre. Os professores foram acompanhados num período de dois meses e esse período correspondeu ao semestre letivo 2016.2 e as disciplinas, cargas horárias, semestres das disciplinas e cursos estão designadas a seguir.

Quadro 1. Acompanhamento dos Professores nas Disciplinas e Cursos Investigados

\begin{tabular}{|c|c|c|}
\hline Professores & Disciplina/ Carga Horária/ Semestre & Curso \\
\hline P1 & $\begin{array}{c}\text { Segurança do Trabalho/ 40h (2을 } \\
\text { semestre) }\end{array}$ & Tecnólogo em Processos Ambientais \\
\hline $\mathbf{P 2}$ & $\begin{array}{l}\text { Fundamentos Sociofilosóficos da } \\
\text { Educação/ 80h (1o semestre) }\end{array}$ & Licenciatura em Química \\
\hline P3 & $\begin{array}{l}\text { Física Básica/ 40h (1o semestre) } \\
\text { Física Geral I/ 80h (3o semestre) }\end{array}$ & $\begin{array}{c}\text { Tecnólogo em Processos Ambientais } \\
\text { Licenciatura em Química }\end{array}$ \\
\hline P4 & $\begin{array}{l}\text { Métodos Computacionais Aplicados à } \\
\text { Área Ambiental/ 80h (4ํsemestre) }\end{array}$ & Tecnólogo em Processos Ambientais \\
\hline
\end{tabular}

Fonte: Ventura (2019)

(C) ETD- Educação Temática Digital Campinas, SP $\quad$ v.22 $\quad$ n.4 $\quad$ p. 1010-1030 out./dez. 2020 
Em adição ao questionário de sondagem, os instrumentos de coleta utilizados foram a observação e a entrevista. Ao observar o professor em momentos formais, foram identificadas, as tecnologias comumente utilizadas, fazendo-se contraposição com as descritas no questionário de sondagem; as estratégias metodológicas utilizadas com e sem o uso das tecnologias; bem como a utilização das tecnologias digitais, exprimindo dificuldades práticas no uso do equipamento. Em momentos informais com os professores, foi possível identificar suas intencionalidades ao utilizar determinada metodologia e tecnologia em detrimento da outra. Tais ações ajudaram na caracterização dos estágios da gestão pedagógica.

Após o período de observação, iniciou-se a análise dos dados, procurando elementos que respondessem ao objetivo proposto. Os que não foram respondidos ou que necessitavam ser aprofundados foram inseridos em questões pontuais da entrevista. Esta teve como objetivo esclarecer e elucidar: as intenções do professor ao utilizar as tecnologias digitais em sala de aula; como estas poderiam favorecer a aprendizagem dos alunos de modo mais participativo e autoral; um comparativo realizado pelo próprio professor acerca de suas aulas com e sem a utilização das tecnologias digitais; a avaliação de seu uso ao utilizar as tecnologias digitais; possíveis mudanças da prática do professor e uma avaliação sobre a percepção dos alunos em relação ao professor quando as tecnologias digitais foram empregadas. E, por fim, acréscimos para aprimorar a sua prática ao relacionar o uso das tecnologias as suas metodologias de ensino, dentre outras.

Para a análise de dados, iniciou-se com as questões de menor amplitude, bem como se definiram códigos iniciais ou subsequentes (YIN, 2010). Fases como ordenação, classificação e análise propriamente dita do material também subsidiaram a análise (MINAYO, 2016). Posteriormente, foram triangulados os dados, sendo estes ancorados pelo paradigma interpretativo (MOREIRA; CALEFFE, 2006). Na referida pesquisa os códigos foram representados pela letra $T$ quando estavam relacionados às tecnologias e representadas pela letra $M$, quando às metodologias, seguindo uma ordem linear de início, meio e fim de uma aula. A seguir, os resultados e discussão dos dados.

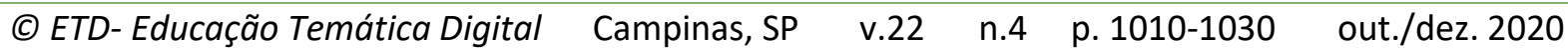




\section{RESULTADOS E DISCUSSÃO DOS DADOS}

Nesta seção apresentar-se-ão os estágios da gestão pedagógica de salas de aulas com uso da tecnologia seguidos de exemplos dos estágios de gerenciamento tecnológico e da gestão pedagógica. A expressão "Gestão Pedagógica" engloba, no trabalho do professor, a organização, a sistematização, a reflexão e tomada de decisão do que será posto em prática, tomando por base o planejamento de todos os elementos do ensino [objetivos, conteúdos, relações professor-aluno, metodologia (estratégias didáticas, recursos, atividades e tempo provável) e avaliação]. Estes elementos devem ser igualmente planejados pelo docente, devendo haver um equilíbrio entre eles. Este equilíbrio pode ser visualizado quando nenhum elemento se sobressai nas ações desenvolvidas pelo professor. Diferente da expressão "Gerenciamento Tecnológico", quando a ideia perpassada é a de, apenas, gerenciar o processo de ensino e aprendizagem, tendo a tecnologia como elemento maior e sobreposto aos demais elementos do ensino.

Por compreender que, para cada estágio tecnológico, o professor deve possuir uma atitude pedagógica, independentemente de qual seja a tecnologia escolhida, foram exemplificados os dois tipos de estágios. A reflexão que deve provocar no docente é a de que os estágios pedagógicos possam desencadear, por meio da consciência crítica, uma nova cultura educativa, tanto em termos de ensino quanto de aprendizagem, potencializando as relações humanas, o dinamismo do processo (início, meio e fim de uma aula) e os papéis que cada um tem ao utilizar as tecnologias. Tais estágios foram desenvolvidos objetivando criar diferentes formas de ensino e aprendizagem com a ajuda da tecnologia.

\subsection{Estágios da Gestão Pedagógica de Salas de Aulas com Uso da Tecnologia}

Os estágios desenvolvidos seguem os princípios de Beauchamp e Childress (1994), ao discutirem que um modelo explicativo pode ser validado quando denota clareza, coerência, completude, simplicidade e poderes explicativo, justificativo e resolutivo.

O estágio um, iniciação, é o do encantamento, da iniciação, da exploração da descoberta da tecnologia e de seu uso por tentativa e erro. Seu objetivo é possibilitar o contato inicial do professor com a tecnologia, mesmo que não haja ainda um planejamento sistematizado que o leve a pensar abstratamente como seu uso pode ajudar o aluno a desenvolver por si próprio, ou seja, assumir a responsabilidade de sua aprendizagem. A intenção inicial é de experimentar as tecnologias disponíveis na instituição e as de conhecimento dos alunos, sendo estes fundamentais para que o professor tome consciência de que a tecnologia deva ser utilizada partindo das necessidades dos discentes e não do

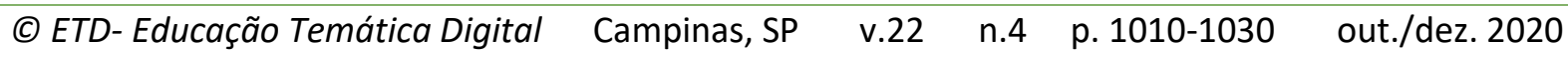


docente. Mesmo que a tecnologia não faça parte das ações diretas do professor, este não descarta a possibilidade de pensar pedagogicamente sobre seu uso e de inseri-la formalmente em seu planejamento.

No estágio dois, a inserção, o professor insere a tecnologia de modo esporádico em seu planejamento. Mesmo que esteja aliada às ações pedagógicas, a tecnologia é utilizada de forma pontual, instrumental e como complemento e apoio às aulas tradicionais. A concepção de que o simples uso da tecnologia pode mudar a prática tradicional é a ideia predominante nesse estágio, pois não há correlação entre o conteúdo curricular, as ações conjuntas do professor e do aluno e os resultados a atingir. Esta falta de correlação não é intencional, mas não há ainda saberes sistematizados para que se efetive tal relação. É a sensação de impacto que a tecnologia pode proporcionar sobre os alunos e não na aprendizagem deles. Mesmo incluindo a tecnologia no currículo, os conteúdos são apresentados linearmente, seguidos de exercícios estruturados, objetivando a comportamentos esperados dos discentes por parte dos docentes.

A instrumentalidade do uso da tecnologia serve de base para que o professor perceba que não houve mudanças na forma como ele ensina, consequentemente na aprendizagem discente, pois a ideia inicial, ao inserir a tecnologia, é apenas a de complemento e apoio às aulas tradicionais. Essa percepção leva os professores ao estágio três, o de integração, que é a reflexão criativa de uma ação intencional que possa provocar mudanças significativas na aprendizagem discente, tornando-os capazes de aprender em ritmo próprio, desvelando suas fragilidades e potencialidades por meio da relação entre tecnologia e Educação. O objetivo do estágio três é criar diferentes formas de ensinar e aprender com a ajuda da tecnologia, desmitificando a ideia de que ela determina o que deve ser ensinado e aprendido.

Definem-se questões de administração da sala de aula e disciplina, (re)definem-se papéis de professor e aluno, assim, o planejamento conjunto de aulas com os envolvidos no processo educativo, capacitando-os para a gestão eficaz de uma aula, mediada pela tecnologia. A aula planejada passa a ser centrada no aluno e não mais nas ações do professor. O currículo é (re)significado, porque inclui as concepções tecnológicas e pedagógicas da tecnologia, estudos sistemáticos do docente sobre conceber, gerir e avaliar os processos de ensino e aprendizagem com o uso da tecnologia.

No estágio quatro, ocorre a efetivação do uso pedagógico da tecnologia. É o uso aprimorado do estágio anterior. Professor e aluno utilizam as tecnologias numa relação horizontal, sendo as ideias, dúvidas e práticas partes naturais do processo educativo. A ênfase não recai no uso da tecnologia, mas nos processos de indagação, questionamento, perguntas e elaboração conjunta de saberes que a tecnologia pode proporcionar (se utilizada com essa finalidade). É nesse estágio que ocorre a aprendizagem ativa. $\mathrm{O}$ ativo diz respeito a colocar o

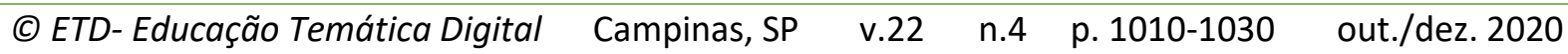


aluno em situações propícias de aprendizagem, sendo a imaginação do professor (re)criada a cada instante. Os papéis do professor e do aluno se confundem o tempo todo em razão da similaridade de papéis, troca de ideias e de atividades realizadas.

No estágio cinco ocorre a disrupção. É o amadurecimento do ciclo da aprendizagem (desconstrução-reconstrução-desconstrução), em que professor e alunos são capazes de recriar (reinventar) a solução para um problema já solucionado. A tecnologia não induz, mas aumenta o repertório de possibilidades para uma reflexão mais aprofundada do processo de ensinar e aprender mediado por ela (tecnologia). Significa pensar em abstrações mais complexas para favorecer a aprendizagem do discente. $O$ docente não apenas utiliza a tecnologia, mas também diferencia em que momento uma é mais viável de ser utilizada do que a outra, exigindo de si uma mudança de atitude pessoal (de suas concepções iniciais e pré-conceitos) e organizacional (no contexto), que não se adquire somente com as experiências dos estágios anteriores e formações continuadas.

Portanto, os estágios propostos ajudam o professor a planejar sua prática de forma mais pedagógica do que tecnológica, bem como auxiliam a orientar pedagogicamente e com maior segurança um aluno que tenha mais familiaridade em determinada tecnologia do que ele. Se há essa troca desde o início de quem sabe o quê, minimiza-se a probabilidade de centralizar o processo educativo no docente, pois, enquanto o aluno sabe mais sobre o uso tecnológico, o professor equilibra o processo de aprendizagem com orientações de cunho pedagógico ou vice-versa. Os resultados foram apresentados como eventos e referentes às transcrições das entrevistas ${ }^{3}$ ou conversas informais.

\subsubsection{Professor 1}

$\mathrm{P}^{4}{ }^{4}$ utilizou, frequente e continuamente, as tecnologias em sua prática docente, revelando tanto um desejo pessoal quanto uma necessidade sua e da área de que faz parte, sendo a tecnologia utilizada com três sentidos distintos, como se pode visualizar.

\footnotetext{
${ }^{3}$ Foram transcritas literalmente, não havendo correções gramaticais correspondentes à norma culta.

${ }^{4}$ P1 e P2 são do sexo feminino, já P3 e P4 são do sexo masculino. Em alguns momentos, a referência à P1 e P2 aparecerá no feminino.

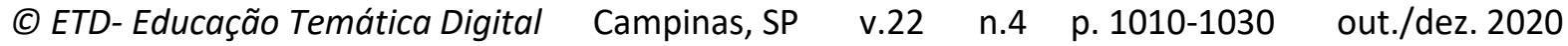


Evento 1 (Entrevista realizada no dia 25/10/2017).

Pesquisadora: Como você descreveria o uso das tecnologias de modo que elas favorecessem a aprendizagem dos alunos de modo mais ativo, [...] e que eles participassem mais [...]?

P1: [...] Eu sempre quero que eles tragam a tecnologia. E eu não sei mais trabalhar só com lousa e pincel. Não consigo. Não gosto. Não gosto. Acho chato. Acho que tem tanta coisa. A internet tem tanta coisa legal, tanto vídeo, que não tem porque não usar, pelo menos na minha área né, que é ambiental. Como eu vou falar de vegetação, se eu não mostro a vegetação, se eu não mostro o problema? [...] As tecnologias também é mais para suprir essa minha deficiência na disciplina. Eu não tenho formação específica pra isso.

Pela caracterização do evento 1 , percebem-se tanto estágios de gerenciamento tecnológico quanto da gestão pedagógica de uso da tecnologia. Quando P1 é questionada sobre como a tecnologia pode favorecer processos mais autorais de aprendizagem, a sua ideia é a de que eles já tragam a tecnologia para a sala de aula, não sendo, portanto, utilizada apenas a que P1 trouxer (algo imposto e somente de seu desejo).

Se P1 tem essa consciência, significa possuir abertura a novas possibilidades em relação ao uso da tecnologia, atitude esta caracterizada pelo estágio três de gerenciamento tecnológico, o de adaptação. Neste estágio, a tecnologia é integrada totalmente na prática do professor e utilizada com muita frequência, mesmo que a predominância seja a aula expositiva. Essa frequência pode ser compreendida quando P1 diz: "[...] não sei mais trabalhar só com lousa e pincel", pressupondo uso contínuo da tecnologia.

A consciência de P1 de utilizar uma tecnologia que seja do interesse do aluno e que parta de suas necessidades é característica do estágio um, o de iniciação, da gestão pedagógica de uso da tecnologia em sala de aula. Já neste estágio inicial, o professor conhece a tecnologia de intenção do aluno e começa a sistematizar, ainda que de modo elementar, como ela será trabalhada, pois expressou estar aberta a novas possibilidades educativas ao proceder do interesse do aluno e reconhecer a importância desse uso em sua prática.

P1 oscila entre o estágio um (iniciação) e o dois (inserção) da gestão pedagógica. Ao mesmo tempo em que não evidenciou possuir dificuldades ao utilizar a tecnologia em suas aulas, possui características do estágio dois, pois utiliza a tecnologia de forma pontual e instrumental, ao reconhecer que exagera no uso demasiado de slides e que poderia não utilizar tanto. Apesar de reconhecer esse exagero, não pontua nenhuma ação diferente.

O segundo sentido de uso da tecnologia, demonstrado no referido evento, ser uma necessidade de $\mathrm{P} 1$, é visualizado quando diz que a tecnologia serviu também para suprir uma deficiência em decorrência da sua falta de formação na disciplina ministrada (Segurança do Trabalho), sendo a sua formação inicial em Geografia. Nesse sentido, P1 utilizou a tecnologia como mais um recurso para viabilizar, auxiliar e complementar seus saberes teóricos.

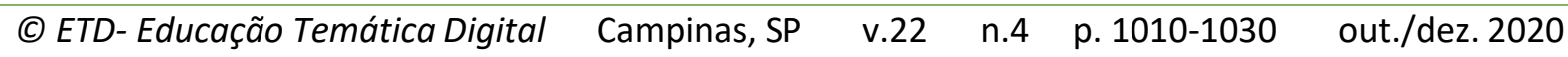


O terceiro sentido de uso da tecnologia, uma necessidade da área, pode ser percebido quando P1 diz "Como eu vou falar de vegetação, se eu não mostro a vegetação, se eu não mostro o problema?". Ou seja, a visualização do concreto precisa acontecer numa disciplina como a que ela ministrou, Segurança do Trabalho, necessitando ir além da abstração e da teorização. A seguir, a análise dos estágios na prática de P2.

\subsubsection{Professor 2}

P2 recorreu às tecnologias em sua prática pedagógica com finalidades diferentes: para complementar uma ideia já discutida em sala de aula ou com uma finalidade específica, no caso, o fator motivacional, com o uso de vídeos e músicas, preocupando-se sempre em articular com o objetivo da aula. O evento a seguir traz um exemplo dos estágios da gestão pedagógica:

Evento 2 (Entrevista realizada no dia 12/11/2017).

Pesquisadora:[...] o que você acrescentaria que poderia ser aprimorado em sua prática ao relacionar o uso das tecnologias a suas metodologias de ensino?

P2: Eu penso que seria avançar nas leituras teóricas. [...] Primeira coisa é conhecer os teóricos. [..] eu penso que a concepção de Serafim Alava é diferente da Kenski e por aí vai. Cada um, mesmo sendo das tecnologias, eles têm uma forma de pensar. Então, quando você compreende essa concepção, compreende mesmo, isso também te ajuda a empreendê-las, né, no dia a dia da escola, da sala de aula, no cotidiano escolar. Eu teria que avançar nessa concepção teórica exatamente pra eu ver se eu chego com segurança, né, na realização, do que eu posso fazer, do que eu posso trazer, né, o que eu posso desenvolver na prática, falando mesmo em termo midiático que isso me ajuda nas atividades didáticas-pedagógicas, entendeu? [...] E eu percebo também que têm alguns professores que dominam muito as tecnologias, mas dominam que tipo de tecnologias? Às vezes, é o Face que chega a ser um vício, às vezes é o WhatsApp, mas não é uma tecnologia voltada para o âmbito didático, pedagógico. O que que isso aqui ajuda na construção do conhecimento com o meu estudante, o que que isso ajuda, o que isso aqui faz avançar na minha prática, no fazer didático-pedagógico? Considerando que é isso que eu vejo como necessidade de aprender. Não quero me tornar uma pessoa viciada em WhatsApp, viciada em Face, não. Eu quero fazer uso dessas tecnologias, que eu possa realmente contribuir com a minha prática e que possa ser útil também para os estudantes e que não possa também ser um peso para os estudantes. [...]

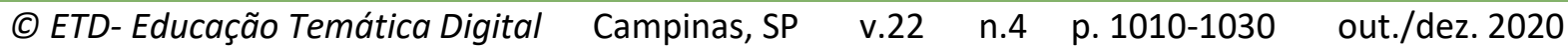


Vários elementos enriquecem a prática pedagógica de P2. O primeiro é a necessidade de conhecer a epistemologia que rege as tecnologias na Educação. Aliado a essa necessidade, acrescenta-se também a de conhecer as potencialidades e fragilidades de cada tecnologia, visando a alcançar o objetivo da aula. Quando P2 destaca que o Facebook e o WhatsApp não são tecnologias voltadas para o âmbito didático, demonstra desconhecimento de que tais ferramentas, se utilizadas pedagogicamente e com finalidades específicas, podem desencadear processos autorais, participativos, interativos e colaborativos de aprendizagem ativa.

Segundo, P2 já conhece autores da área, o que diminui a distância entre conhecer e fazer, podendo desenvolver uma ação com segurança, como destaca em sua fala. Terceiro, se se conhecem as ideias desses autores (citando Alava e Kenski), será capaz de utilizá-las com propriedade no cotidiano de sua sala de aula. Quarto, a possibilidade de mudança no planejamento de atividades. Quinto, utilizar uma tecnologia que ajude na formação de seu aluno e não somente por modismo, como finaliza o evento 2: "Eu quero fazer uso dessas tecnologias, que eu possa realmente contribuir com a minha prática e que possa ser útil também para os estudantes e que não possa também ser um peso para os estudantes [...]".

Os aspectos do fazer pedagógico de P2 estão solidificados numa concepção de aprender a aprender e que esse aprender implica uma mudança prática de suas ações e na de seus alunos, indo além da consciência de reconhecer o potencial tecnológico e pedagógico. Todas as ideias expressas caracterizam o estágio dois da gestão pedagógica com uso da tecnologia, o de inserção.

No que diz respeito ao estágio de gerenciamento tecnológico, P2 se encontra no três, o de adaptação, caracterizado pela inserção de diversas tecnologias, como o vídeos, slides, dentre outras, ainda que não se tenha visualizado uma prática mais elaborada com o uso da tecnologia. Para exemplificar o estágio de gerenciamento tecnológico, P2 destaca:

Evento 3 (Entrevista realizada no dia 12/11/2017).

Pesquisadora: É interessante quando os professores são a favor da tecnologia, mas quando tu utiliza a tecnologia, qual a avaliação que tu faz, tu acha que era isso mesmo que tu queria ou, então, quando tu termina a aula diz: eu acho que poderia ser diferente ou, então, eu tô no caminho, mas ainda não é tudo que eu desejo. Era isso mesmo, porque às vezes a gente acha que não alcança o objetivo. E na tua prática?

P2: Eu penso que como eu não tenho conhecimento pleno, como eu também não tenho, quando você não domina plenamente, eu não sofro por achar que não atingi. Porque eu ainda trabalho, o que eu uso, uso com essa consciência, de que eu não sou a top ou a bam bam bam na área tecnológica.

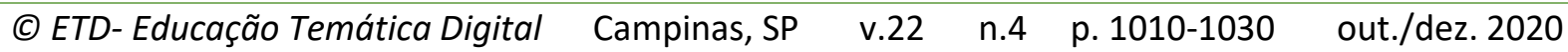


P2 reconhece suas limitações tecnológicas, mas não deixa de fazer uso das tecnologias, mesmo não as dominando plenamente, sendo esta uma prática correta. Essa consciência tecnológica de não abandonar o uso da tecnologia, por não ser experta em tecnologia, deve ser complementada à consciência pedagógica (já demonstrada no evento 2 ), pois tanto os estágios de gerenciamentos tecnológico quanto os da gestão pedagógica devem caminhar juntos, um em função do outro. Ou seja, o primeiro deve ser utilizado por uma necessidade do segundo, respectivamente, fazendo com que a reflexão ocorra na ação (de planejar e pôr em prática).

Ao afirmar que P2 se encontra no estágio três de gerenciamento tecnológico, percebese um avanço quando comparado à pesquisa de Silva et al. (2014), ao explicitarem que os professores da Educação Superior se encontram em níveis iniciais de apropriação tecnológica. Defende-se o argumento que o estágio três não é inicial, mas sim intermediário, sendo o professor capaz de usar o artefato ainda que com alguma dificuldade ou com auxílio. A seguir, reflexões sobre os estágios na prática de P3.

\section{Professor 3}

A prática de P3 foi permeada de tecnologias e utilizada desde a realização da frequência discente em seu Iphone ou tablet, até a aula propriamente com slides, vídeos e simuladores. Para a elaboração de slides fez uso do Latex, programa para diagramação de textos, utilizado na produção de textos matemáticos e científicos. A utilização frequente desse uso foi percebida em momentos de observação e ratificada na entrevista.

Sobre os estágios de gerenciamento tecnológico, P3 demonstra estar no último, o de inovação ou invenção. Tal afirmação é validada quando P3 foi capaz de experimentar padrões diferenciados e formas de se relacionar com os alunos, quando propôs trabalhar a resolução de problemas por meio de projetos interdisciplinares, ao solicitar aos alunos a elaboração de um Canhão de Batatas para discutir o conteúdo Lançamento de Projétil. Apesar de o projeto ter sido uma iniciativa do professor, a atividade propiciou aos alunos autonomia, protagonismo, elaboração de hipóteses, criatividade, interação e integração entre os participantes, sendo estas características de metodologias ativas.

Utiliza a tecnologia de forma intencional, pois afirma que não há como mostrar determinados conceitos físicos em sala de aula por falta de experimento ou dinheiro e com o computador se quebra essa barreira. Se P3 sabe onde chegar, há consciência de planejar uma aula com tecnologia. Essa consciência é melhor exemplificada quando Ihe foi perguntado:

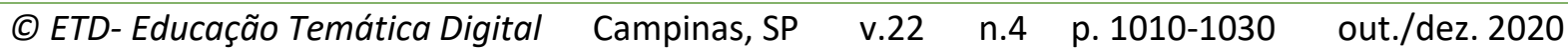


Evento 4 (Entrevista realizada no dia 30/10/2017)

Pesquisadora: Pela nossa conversa, o que você acrescentaria que poderia ser aprimorado em sua prática ao relacionar metodologia e tecnologia?

P3: Eu posso dizer que eu sou um leigo, né, em tecnologia porque eu sei usar. Mas não sei se, para cada tipo de tecnologia, tem um porquê aquela tecnologia foi criada, aborda alguma teoria da educação. Eu não sei quais são essas teorias. Então eu uso na doida, né, se posso dizer assim. E dá certo, mas se eu tivesse um embasamento teórico maior eu acho que seria bem melhor. [...] Às vezes eu nem sei se é o melhor momento pra usar a tecnologia e eu vou lá e uso, né? Então esses pormenores é que eu não sei.

A fala de P3 caracteriza o estágio três da gestão pedagógica, o de integração, caracterizado por uma ação intencional que provoque mudanças na aprendizagem discente. Essa mudança só foi visualizada quando P3 se propôs trabalhar com a resolução de problemas por meio do projeto "Canhão de Batatas". Nesse momento demarcado, os alunos se assumiram tanto como autores de sua aprendizagem como consumidores da informação, quando consumiram as explicações teóricas, expostas por P3.

Apesar do estágio quatro, o de efetivação, ser um aprimoramento do estágio três e possuir uma característica referente àquele estágio, a de promover situações propícias para desencadear a aprendizagem ativa, não se pode afirmar que P3 se enquadre nesse estágio porque demonstrou no evento 4 desconhecer as teorias epistemológicas que circundam e embasam as tecnologias na Educação. Apesar de planejar sua aula com tecnologia, demonstra também fazer uso por tentativa e erro, quando diz que usa a tecnologia "na doida", o que descaracteriza totalmente o estágio de efetivação de uso pedagógico da tecnologia. O estágio quatro é a superação ingênua dos aspectos pedagógicos e tecnológicos correlacionados e não apenas de um, como demonstra P3 estar num nível tecnológico mais avançado do que o pedagógico no que diz respeito ao uso da tecnologia. A seguir, as análises referente a P4.

\subsubsection{Professor 4}

A disciplina "Métodos Computacionais Aplicados à Área Ambiental", ministrada por P4, foi a única das analisadas que exigiu a utilização das tecnologias digitais por sua própria natureza. Ainda que no instrumento de coleta "Entrevista" houvesse perguntas gerais, todas as respostas de $\mathrm{P} 4$ foram direcionadas às tecnologias e, por esta razão, foram extraídos somente trechos que estivessem direcionados aos estágios da gestão pedagógica e aos de gerenciamento tecnológico com o uso da tecnologia.

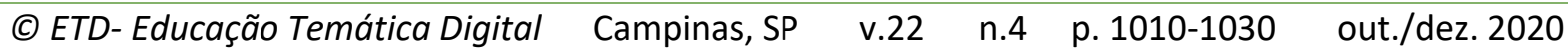


No que diz respeito ao gerenciamento tecnológico, quando é perguntado a P4 se a sua disciplina daria para ser com outra tecnologia que não fosse o software Stella, responde que sim e cita vários outros softwares ${ }^{5}$ no decorrer da entrevista, e não somente em uma questão específica; daí não referenciar num só evento. Afirmou que existem softwares de modelagem dinâmica bem interessantes, como o software Simile, "[...] que é um software proprietário como o Stella, mas ele é pra Linux", o software Vsim, "[...] que é um sistema alemão, utilizado pro C-Roads e que utiliza a mesma linguagem de diagramatização via Forrest", o software OpenModelica " "[...] que funciona como um grande simulador" e "[...] é um software muito poderoso pra muitas outras coisas"; "[...] tem um sisteminha chamado gazebo ${ }^{7}$, que é muito legal, que ele faz simulações, sistema de simulações em três dimensões".

Tais ponderações acerca do conhecimento tecnológico de P4 levam a afirmar que ele se encontra no estágio cinco de gerenciamento tecnológico, o de inovação ou invenção. A descrição desse estágio se fortalece quando é perguntado a P4 quando ele descobriu o software Stella, se havia sido na graduação, e a resposta foi que sim. Disse ainda que, no decorrer da graduação, havia feito um curso de Análise de Sistemas e Modelagem Ambiental, sendo, na época, considerado por P4, "uma asma", ao se referir ser a febre do momento. Disse também que um dos professores de sua graduação, por ter desenvolvido vários modelos em seu mestrado, trouxe novas visões de modelos computacionais, possibilitando outras pessoas a interagirem mais detidamente com este software, o Stella.

Posteriormente, P4 afirmou que, ao entrar no mestrado e já participando de grupos de estudos, realizou o curso completo, de cinco módulos, do software Stella com um professor do Centro de Tecnologia da Califórnia, demonstrando mais uma vez possuir domínio tecnológico nessa determinada tecnologia. Pelos relatos descritos, percebe-se seu conhecimento teórico, o da existência de vários softwares, conhecimento este que pode ou não levar ao conhecimento prático.

Em outro momento da entrevista diz: "[...] É mais uma brincadeira de fechamento da disciplina. Eles têm acesso a um outro patamar computacional. É uma outra tecnologia", mostra a concretude da teoria, da demonstração prática de mais uma linguagem computacional. Tais ideias mostram implicitamente que P4 não apenas sabe da existência de inúmeros softwares, mas que também pode promover situações contextuais diferenciadas por meio desse conhecimento teórico.

\footnotetext{
${ }^{5}$ Os softwares que não estão linkados não possuem site oficial.

${ }^{6}$ Disponível em: $<$ https://bit.ly/2DOw69N $>$ Acesso em 20 out. 2019.

${ }^{7}$ Disponível em: <https://bit.ly/2smcYwO > Acesso em: 20 out. 2019.

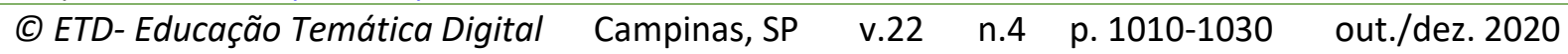


No que diz respeito ao estágio da gestão pedagógica de uso da tecnologia, é possível essa compreensão quando lhe foi perguntado:

Evento 5 (Entrevista realizada no dia 25/10/2017).

Pesquisadora: Qual a importância que você atribui à tecnologia na sua prática? P4: [...] a tecnologia vem a ser uma ferramenta aliada ao desenvolvimento de algo que está na abstração dele. Então, ele começa a ver que a tecnologia nada mais é do que uma ferramenta, tá, pra algo muito maior. A ideia da tecnologia, do computador, do desenvolvimento do computador, das tecnologias colocadas no computador é fantástica, tá, que jamais vai alcançar.

A conscientização que P4 possui sobre a tecnologia como meio e não como fim faz com que o aluno perceba isso sozinho. Ao ser capaz de planejar situações para que essa percepção aconteça, afirma-se que P4 está num estágio intermediário da gestão pedagógica de uso da tecnologia, o três, o de integração. Tal estágio se caracteriza como uma ação intencional que pode provocar mudanças na aprendizagem dos alunos, tornando-os capazes de aprender em ritmo próprio, desvelando suas fragilidades e potencialidades por meio da relação tecnologia e educação. P4 alcança o objetivo do estágio três, criando formas diferentes de ensinar e aprender com a ajuda da tecnologia, desmitificando a ideia de que é ela a determinar o que deve ser ensinado e aprendido, como se pôde visualizar especificamente no último evento.

Não se pode afirmar que seu estágio seja o quatro (o de efetivação), pois reconhece precisar de base metodológica ao ser perguntado sobre a necessidade de atualização, tanto no que diz respeito às metodologias utilizadas quanto às tecnologias digitais. Se não existe essa base, a efetivação pedagógica não acontece, porém é fácil de ser adquirida, já que P4 se encontra no último nível de gerenciamento tecnológico. Nesse caso, necessitaria de um equilíbrio entre o pensar pedagógico da tecnologia, demonstrando já possuir, e a utilização da tecnologia.

A tabela 1 traz um resumo dos estágios de gerenciamento tecnológico e da gestão pedagógica, por professor.

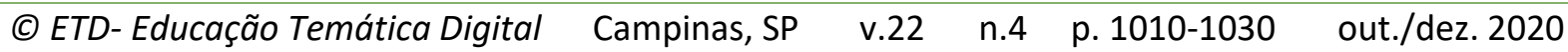


TABELA 1. Estágios de Gerenciamento Tecnológico (EGT) e Estágios da Gestão Pedagógica (EGP) por Professor

\begin{tabular}{|c|c|c|}
\hline Professor & Estágios de Gerenciamento Tecnológico & Estágios da Gestão Pedagógica \\
\hline P1 & 3 & 2 \\
\hline P2 & 3 & 2 \\
\hline P3 & 5 & 3 \\
\hline P4 & 5 & 3 \\
\hline
\end{tabular}

Fonte: Ventura (2019).

Na tabela 1 são mostrados os estágios de gerenciamento tecnológico e da gestão pedagógica em que cada professor se encontrou no período da investigação. Ainda que não seja uma regra, é importante o professor dominar as tecnologias disponíveis na instituição, as que o aluno deseja utilizar e aquelas com as quais o docente se propõe trabalhar, tendo em vista que o domínio pedagógico surge pela necessidade do tecnológico e não o contrário.

Em nenhum momento, a análise acerca dos estágios se deteve em avaliar se o uso da tecnologia foi utilizado corretamente ou não. Preservaram-se as especificidades de cada professor, tanto no que diz respeito a sua "falta de habilidade" ou "destreza tecnológica e pedagógica" com o uso das tecnologias. É importante relativizar quando se trata de seres humanos, culturas específicas, no caso, a Educação Superior, contexto e práticas de ensino, pois estas se atualizam constantemente. A seguir, as conclusões deste estudo.

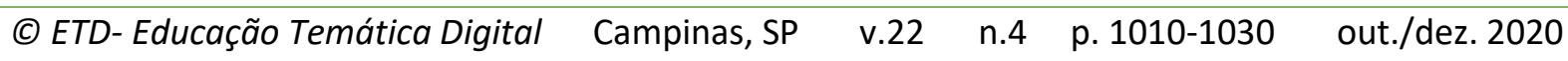




\section{CONCLUSÕES}

Este artigo teve como objetivo propor estágios da gestão pedagógica para o uso das tecnologias digitais quando as metodologias ativas foram utilizadas. Ainda que o saber tecnológico seja necessário ao professor (para ser considerado um incluído social e digital nas práticas sociais educacionais contemporâneas), foi exigido que se oferecesse, na posição de investigadora, uma análise das intencionalidades e preferências de uso de determinadas tecnologias, aplicativos e equipamentos digitais em detrimento de outras.

Exprime-se, também, que o saber tecnológico é um saber inerte que pouco pode promover resultados significativos à aprendizagem discente se dissociado da intencionalidade pedagógica do docente. Por este motivo, foram desenvolvidos estágios da gestão pedagógica para analisar as práticas dos professores quando as tecnologias foram inseridas, fosse em momentos específicos, como no caso de P1, P2 e P3, ou durante toda a disciplina, como ocorreu com P4.

Independentemente se o docente utiliza ou não as tecnologias, os estágios desenvolvidos são sugestivos ao trabalho pedagógico com as tecnologias digitais, os quais visam a instigar uma reflexão acerca do assunto em questão. Tal reflexão ocorrerá se houver abertura do professor e mudança de mentalidade. Se novos referenciais teóricos são desenvolvidos com base numa situação vivida, a probabilidade de adoção é maior, pois o docente partirá de uma situação concreta, aproximando teoria e prática.

Tão importante quanto o uso é saber em que momento uma tecnologia é mais viável do que outra, assim como a intencionalidade de uso. Ainda que não estivesse diretamente relacionado ao objetivo deste estudo, os quatro professores demonstraram o desejo de atualização, tanto no que se refere às suas metodologias (no sentido de conhecer a diversidade delas e de saber utilizá-las) quanto às tecnologias. Esse reconhecimento implica, diretamente, saber teórico e prático, sendo que um saber (prático) se faz pela necessidade do outro (teórico). O primeiro passo dos quatro professores foi a tomada de consciência sobre a necessidade de atualização, aprimoramento da prática docente e abertura a novas possibilidades, demonstrando que professores atuantes na Educação Superior já caminham conscientemente para uma nova atitude pedagógica com o uso das tecnologias digitais. A pesquisa ora realizada valida essa afirmação quando P1, P2, P3 e P4 reconhecem as contribuições que as tecnologias trazem no uso de suas metodologias, defendendo seu uso na aula universitária.

Considera-se o professor como protagonista principal, quando da concretização da integração das tecnologias em sua prática pedagógica. Se utilizada, não deve representar somente uma inovação tecnológica, mas, principalmente, pedagógica. Essa premissa implica

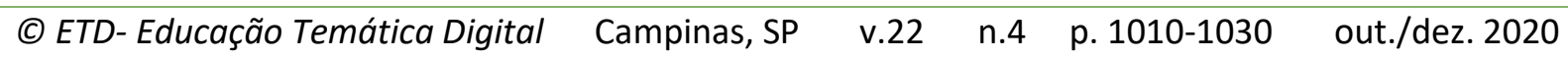


na instituição ora analisada promover espaços de formação em três vertentes: a tecnológica (ampliando a visão da racionalidade/instrumentalização técnica e do uso pelo uso), traduzida em conhecimentos sobre a manipulação e operacionalização do recurso tecnológico disponível na instituição como também de recursos via web, sendo estes recursos de interesse do aluno. Nas vertentes pedagógica e metodológica, impõem-se orientações que viabilizem a integração das tecnologias na prática do docente, discutindo eventos reais vivenciados em sala de aula, sendo esses nas áreas do conhecimentos dos professores da instituição analisada.

\section{REFERÊNCIAS}

ABEGG, Ilse; BASTOS, Fábio da Purificação de. Convergência e integração de tecnologias criativas em ambientes virtuais. Educ. Temat. Digit. Campinas, SP. v.18. n.1, p.60-70, jan./abr. 2016.

ALMEIDA, Maria Elizabeth Bianconcini; VALENTE, José Armando. Tecnologias e currículo: trajetórias convergentes ou divergentes? São Paulo: Paulus, 2011.

BEAUCHAMP, Tom; CHILDRESS, James. Principles of biomedical ethics. 4 ed. New York: University Press, 1994.

COSTA, Fernando Albuquerque. Competências TIC: estudo de implementação. Lisboa: GEPE; Ministério da Educação (MEC), 2008.

DIAS, Paulo. Aprendizagem colaborativa e comunidades de inovação. In: ALMEIDA, Maria Elizabeth Bianconcini; DIAS, Paulo; SILVA, Bento Duarte da (Org.). Cenários de inovação para a educação na sociedade digital. São Paulo: Loyola, 2013.

DIAS, Paulo. Relatório da disciplina de hipertexto. Braga: Universidade do Minho, 1995.

ISTE. National educational technology standards for teachers: preparing teachers to use technology. Eugene: ISTE, 2008.

MINAYO, Maria Cecília de Souza (Org.); DESLANDES, Suely Ferreira; GOMES, Romeu. Pesquisa social: teoria, método e criatividade. Petrópolis, RJ: Vozes, 2016.

MODELSKI, Daiane; GIRAFFA, Lúcia Maria Martins; CASARTELLI, Alam de Oliveira. Tecnologias digitais, formação docente e práticas pedagógicas. Educ. Pesqui., São Paulo, v.45, 2019.

MOREIRA, Herivelto; CALEFFE, Luiz Gonzaga. Metodologia da pesquisa para o professor pesquisador. Rio de Janeiro: DP\&A, 2006.

ROSA, Fernanda R.; AZENHA, Gustavo S. Aprendizagem móvel no Brasil: gestão e implementação das políticas atuais e perspectivas futuras. São Paulo: Zinnerama, 2015.

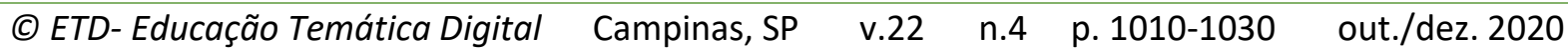


SANDHOLTZ, Judith Haymore; RINGSTAFF Cathy; DWYER, David C. Ensinando com tecnologia: criando salas de aula centradas nos alunos. Tradução: Marcos Antônio Guirado Domingues. Porto Alegre: Artes Médicas, 1997.

SILVA, Bento. A tecnologia é uma estratégia. II Conferência Internacional Challenges' 2001/ Desafios' 2001.

SILVA, Bento; ARAÚJO, Alexandra; VENDRAMINI, Claudette; MARTINS, Ronei; PIOVEZAN, Nayane; PRATES, Eli; DIAS, Anelise; ALMEIDA, Leandro; JOLY, Maria Cristina. Aplicação e uso de tecnologias digitais pelos professores do ensino superior no Brasil e Portugal. Educação, Formação \& Tecnologias, v.7, n.1, p.3-18, 2014.

TARDIF, Maurice. Saberes docentes e formação profissional. 2 ed. Petrópolis: Vozes, 2002.

UNESCO. Padrões de competência em TIC para professores. Paris: Unesco, 2009.

VENTURA, Paula Patrícia Barbosa. Indicadores de metodologias ativas com suporte das tecnologias digitais: estudo com docentes do Instituto Federal de Educação, Ciência e Tecnologia do Ceará. 2019. 195f. Tese (Doutorado) - Universidade Federal do Ceará, 2019.

VOSGERAU, Dilmeire Sant'Anna Ramos; PASINATO, Nara Maria Bernardes. Proposta de indicadores para avaliação dos estágios de integração das TIC no contexto escolar. In: ALMEIDA, Maria Elizabeth Bianconcini; DIAS, Paulo; SILVA, Bento Duarte da (Org.). Cenários de inovação para a educação na sociedade digital. São Paulo: Loyola, 2013.

YIN, R. K. Estudo de caso: planejamento e métodos. 4 ed. Porto Alegre: Bookman, 2010.

Revisão gramatical realizada por: Susane Machado Teixeira.

E-mail: susanemachadot@gmail.com

(C) ETD- Educação Temática Digital $\quad$ Campinas, SP $\quad$ v.22 $\quad$ n.4 $\quad$ p. 1010-1030 out./dez. 2020 